This is an electronic reprint of the original article. This reprint may differ from the original in pagination and typographic detail.

Author(s): Chen, Chengcong; Alén, Raimo; Lehto, Joni; Pakkanen, Hannu

Title: $\quad$ Combustion Properties of Birch (Betula pendula) Black Liquors From Sulfur-Free Pulping

Year: $\quad 2016$

Version:

Please cite the original version:

Chen, C., Alén, R., Lehto, J., \& Pakkanen, H. (2016). Combustion Properties of Birch (Betula pendula) Black Liquors From Sulfur-Free Pulping. Journal of Wood Chemistry and Technology, 36(6), 401-411. https://doi.org/10.1080/02773813.2016.1203945

All material supplied via JYX is protected by copyright and other intellectual property rights, and duplication or sale of all or part of any of the repository collections is not permitted, except that material may be duplicated by you for your research use or educational purposes in electronic or print form. You must obtain permission for any other use. Electronic or print copies may not be offered, whether for sale or otherwise to anyone who is not an authorised user. 


\title{
COMBUSTION PROPERTIES OF BIRCH (Betula pendula) BLACK LIQUORS FROM SULFUR-FREE PULPING
}

\author{
C. Chen, R. Alén, J. Lehto, and H. Pakkanen \\ Laboratory of Applied Chemistry, Department of Chemistry, University of Jyväskylä, Jyväskylä,
} Finland

Sulfur-free pulping has an environmental advantage over the traditional kraft process. This paper describes the combustion properties of the black liquors produced from silver birch (Betula pendula) sawdust using three different cooking processes: two sulfur-free cooks (sodaanthraquinone and oxygen-alkali), and one reference kraft cook. It also considers the corresponding black liquors from an integrated forest biorefinery, in which a hot-water pretreatment of feedstock was performed prior to pulping. With the same cooking time, the total burning times for the sulfur-free black liquors were higher (15-55\%) than those for the conventional kraft black liquors. However, no significant differences were noted between the total burning times for black liquors from pretreated feedstock and those from untreated feedstock. Especially in the case of untreated feedstock, the results showed that the kraft black liquors typically swelled more (25-45\%) than the sulfur-free black liquors. It was further observed that the kraft and soda-anthraquinone black liquors from the untreated feedstock swelled more than those from the pretreated feedstock, while the oxygen-alkali black liquors swelled less.

Keywords: Aliphatic carboxylic acids, Betula pendula, black liquor, combustion properties, hotwater pretreatment, kraft pulping, lignin, sulfur-free pulping 


\section{INTRODUCTION}

In the pulp and paper industry, the principal delignification process for the manufacture of papermaking fibers is kraft pulping using aqueous sodium hydroxide and sodium sulfide as the cooking chemicals. ${ }^{[1,2]}$ In addition, environmentally friendly delignification methods have been developed, mainly because of odor problems associated with sulfur-containing emissions; these include processes using sulfur-free cooking chemicals such as soda-anthraquinone (AQ) ${ }^{[3-8]}$ However, due to the possible health risks, ${ }^{[9,10]}$ it has been recommended that the use of AQ should be decreased. For this reason, delignification of wood with oxygen and alkali ${ }^{[11-13]}\left(\mathrm{O}_{2}-\mathrm{NaOH}\right)$ may offer a potential sulfur-free method. One-stage delignification of wood by oxygen in the $\mathrm{pH}$ region 79 has been subjected of numerous studies especially in the 1950-1970s. The characteristic feature of this delignification process is the extensive oxidation degradations of lignin and carbohydrates resulting, for example, in black liquors that have lower heating value than those from the kraft and soda-AQ pulping. The delignification rate in the $\mathrm{O}_{2}-\mathrm{NaOH}$ pulping is usually also slightly lower than that detected in the kraft and soda-AQ pulping.

Modern pulp mills could serve as a platform for achieving more efficient use of wood and nonwood materials. ${ }^{[14-19]}$ One of the most promising techniques involves various pretreatment processes in which wood chips are extracted with pressurized hot water ${ }^{[20,21]}$ and partially solubilized prior to delignification. Pretreatment produces mainly carbohydrate-derived fragments, which can be further converted into value-added chemicals, biofuels, or other biomaterials. ${ }^{[17]}$ For example, hardwoods contain substantial amounts of xylan, which can be partially extracted prior to alkaline pulping. In general, the integration of a pretreatment stage into sulfur-free alkaline pulping is considered an important stage in the development of the biorefinery concept. The pretreatment stage can also be carried out under alkaline conditions. ${ }^{[22-24]}$ 
During the alkaline cooking phase, the polymeric structural constituents of wood (i.e., lignin, hemicelluloses, and cellulose) undergo a series of complicated reactions leading to the formation of degraded lignin fractions and carbohydrate-derived low-molar-mass (low-MM) aliphatic carboxylic acids, together with small amounts of other organics. ${ }^{[25,26]}$ These compounds dissolve in the cooking liquor (black liquor, BL), which is concentrated and then combusted in the recovery furnace for the recovery of cooking chemicals and the generation of energy. ${ }^{[17,27]}$

The combustion properties of BL are usually described in terms of the characteristics of a single liquor droplet during combustion, including the duration of the different combustion stages (i.e., drying, pyrolysis, char burning, and inorganic coalescence) and the swelling behavior. ${ }^{[28-39]}$ Upon rapid heating, the droplet undergoes drying, after which the organic material partially breaks down into combustible gases and light hydrocarbons, producing a luminous flame around the droplet. During the pyrolysis stage, the droplet swells significantly. The organic carbon remaining in the char after pyrolysis is then burned off in the char burning stage, producing a small molten bead consisting of various inorganics (mainly $\mathrm{Na}_{2} \mathrm{SO}_{4}$ and $\mathrm{Na}_{2} \mathrm{CO}_{3}$ ), which need to be recovered.

In a recovery boiler high swelling BL droplets are partly entrained in the flue gas and deposited on the upper furnace, while low swelling droplets are likely to end up in the char bed. ${ }^{[40]}$ Furthermore, low swelling droplets tend to have a long char burning time, and at the same time long drying and pyrolysis times may lead to wet droplets in the char bed. An ideal situation for the combustion properties of BL droplets is that they reach the char bed dry, partially pyrolyzed, and still burning.

Knowledge of single droplet combustion characteristics is important for controlling the combustion of BL, while the recovery stage is affected mainly by the chemical composition of the BL. ${ }^{[17]}$ A large body of data has been published about the thermochemical behavior of various kraft BLs during combustion. However, only limited data are available about the behavior of alkaline BLs from sulfur-free pulping, especially in cases where hot-water pretreatment of feedstock is applied prior to pulping. 
The purpose of this study was to compare the combustion properties of a reference kraft BL with those of birch BLs from two sulfur-free cooks: soda-AQ and $\mathrm{O}_{2}-\mathrm{NaOH}$. In all cases, the cooking experiments were performed with both the untreated and hot-water-treated feedstock. Combustion experiments were carried out with single BL droplets in stagnant air at $800^{\circ} \mathrm{C}$ in a laboratory furnace. The BLs were characterized in terms of the content of aliphatic carboxylic acids and lignin, and based on these analytical data the combustion properties of various BLs were discussed.

\section{MATERIALS AND METHODS}

\section{Raw Materials and Their Analyses}

Experiments were conducted with both the untreated and hot-water-treated silver birch (Betula pendula) sawdust $(<5 \mathrm{~mm})$.

The pretreatments were performed using a pilot-scale flow through extraction reactor (constructed by Viitos-Metalli Ltd., Heinola, Finland) that consisted of a pump, a water-treating unit, a heat exchange system, a hot-water reservoir, an extraction chamber, and extract collection vessels. The water flow rate was controlled by five valves, and the pressure was kept automatically at 20 bars. During extraction, $44.5 \mathrm{~kg}$ of air-dried birch sawdust was extracted $38 \mathrm{~min}$ (a heating-up time of 30 $\min$ ) at $170^{\circ} \mathrm{C}$, and the corresponding $\mathrm{P}$-factor ${ }^{[41]}$ was about 380 (a final $\mathrm{pH}$ of about 3.5 ). After the extraction, the sawdust was immediately removed from the reactor without being washed and airdried at ambient temperature. The wood yield was $71.9 \%$ of the oven dried (o.d.) initial raw material.

The air-dried untreated and hot-water-treated sawdust samples were ground with a Retsch SM 100 cutting laboratory mill (Retsch $\mathrm{GmbH}$, Haan, Germany) equipped with a bottom sieve with trapezoidal holes (perforation size $<1.0 \mathrm{~mm}$ ). Then, the moisture content was determined according to TAPPI T $264 \mathrm{~cm}-97$ in an oven at $105^{\circ} \mathrm{C}$, and the extractives content was determined according to TAPPI T 280 pm-99 with acetone in a Soxhlet apparatus (extraction time $4 \mathrm{~h}$ ). The extract was concentrated nearly to dryness by vacuum evaporation with a rotary evaporator (a Rotavapor 
apparatus Heidolph VV2000 from Gemini BV Laboratory, Apeldoorn, the Netherlands), and drying was finalized under a gentle nitrogen stream to determine the total amount of extractives.

Acid hydrolysis was performed according to TAPPI T $249 \mathrm{~cm}-00$, and the resulting monosaccharides were analyzed as per(trimethylsilyl)ated derivatives using a gas chromatography (GC) system comprising an HP 5890 Series II Plus GC apparatus (Hewlett Packard Company, Wilmington, NC, USA) equipped with a flame-ionization detector (FID). Xylitol (Fluka Chemical Corporation, Seeltze, Germany) served as an internal standard (IS). The column was a DP-1701 capillary column $(60 \mathrm{~m} x$ inner diameter $0.32 \mathrm{~mm}$, with a film thickness of $0.25 \mu \mathrm{m}$; Agilent Technologies, Palo Alto, CA, USA). For each monosaccharide, an IS was calibrated based on a separate run with the corresponding model monosaccharide: arabinose, xylose, galactose, glucose, and mannose (all from Fluka Chemical Corporation, Seeltze, Germany). It was then possible to perform peak identification and obtain the mass-based response factor between each monosaccharide and the corresponding IS.

The lignin content of the wood samples was calculated as the sum of the acid-insoluble lignin (Klason lignin) and the acid-soluble lignin according to TAPPI T 222 om-98 and TAPPI T 250 UM. The acid-soluble lignin content was determined with a Beckman DU 640 UV/Vis spectrophotometer (Beckman Instruments Inc., Fullerton, CA, USA) at $205 \mathrm{~nm}$ after quantitative dilution of the sulfuric acid hydrolysate until the absorbance $A$ was in the range $0.3-0.8$. The concentration of the dissolved lignin $c\left(\mathrm{~g} \mathrm{~L}^{-1}\right)$ was calculated as

$$
c=A /(a \cdot b),
$$

where $a$ is the absorptivity $\left(110 \mathrm{~L} \mathrm{~g}^{-1} \mathrm{~cm}^{-1}\right),{ }^{[42]}$ and $b$ is the length of the light path $(\mathrm{cm})$. 


\section{Black Liquors and Their Analyses}

Soda-AQ, $\mathrm{O}_{2}-\mathrm{NaOH}$, and kraft BLs were prepared from both the untreated and hot-water-treated birch sawdust by pulping in 1.25-liter rotating stainless steel autoclaves (each charged with about $120 \mathrm{~g}$ of the air-dried feedstock material) heated in oil bath (a CRS Autoclave System 420 from CRS Reactor Engineering AB, Stenkullen, Sweden). In the $\mathrm{O}_{2}-\mathrm{NaOH}$ pulping, pure oxygen was bubbled through the cooking liquor for 5 min prior to charging sawdust into the reactors. Then, the reactors were closed and purged with oxygen through the reactor lid for 2 min to ensure an oxygen atmosphere. At the end of each cook, the autoclaves were removed from the oil bath and cooled rapidly with cold tap water. The BLs were separated from the pulps by pressing and stored in a freezer for further analysis, including the determination of the volatile acid, hydroxy acid, and lignin contents. The pulping conditions and yields are given in Tables 1 and 2, respectively. Pulp yields were calculated on the oven dry basis of the charged feedstock.

Volatile acids (formic and acetic acids) were determined as their benzyl esters by GC/FID. ${ }^{[4]}$ In this analysis, the sodium salts of formic and acetic acids were liberated to their acid forms, converted into tetra- $n$-butyl ammonium (TBA) salts, and then esterified to benzyl esters prior to GC/FID.

Aliphatic hydroxy acids (hydroxy mono- and dicarboxylic acids) were determined as their per(trimethylsilyl)ated derivatives by GC/FID ${ }^{[45]}$ This method involved the conversion of the sodium salts of these acids into their ammonium salts, which were then per(trimethylsilyl)ated prior to GC.

After dilution of $\mathrm{BL}$ with $0.1 \mathrm{M}$ aqueous $\mathrm{NaOH}$, the lignin content was estimated via $\mathrm{UV} / \mathrm{Vis}$ spectrometry at $280 \mathrm{~nm}$ using absorptivity values of $17.1,22.8$, and $20.3 \mathrm{~L} \mathrm{~g}^{-1} \mathrm{~cm}^{-1}$ for soda-AQ, $\mathrm{O}_{2-}$ $\mathrm{NaOH}$, and kraft BLs, respectively. ${ }^{[46]}$ A gel permeation chromatographic (GPC) system (a Waters HPLC equipped with a Superdex 75 gel column using $0.1 \mathrm{M}$ aqueous $\mathrm{NaOH}$ as the eluent) was applied to determine the $\mathrm{MM} \cdot{ }^{[47]}$ For these analyses, the black liquors were diluted with the $\mathrm{NaOH}$ eluent to achieve a dilution ratio of 1/20. 
The BL dry matter content was determined according to TAPPI T650 om-09. The kappa numbers of the pulps were determined according to SCAN-CI:59.

\section{Droplet Combustion}

The BL samples were evaporated under reduced pressure with a Rotavapor apparatus at $40^{\circ} \mathrm{C}$ to a dry solids content of 55-65\%. Then, 15-20 individual droplets around $9 \mathrm{mg}$ in mass were formed with help of a thin glass rod and combusted in a laboratory furnace in stagnant air at $800^{\circ} \mathrm{C}$, as described elsewhere. ${ }^{[38]}$ The progression of droplet combustion was recorded by a high definition video camera. Using VirtualDub software, the pyrolysis and char burning times were obtained based on the dry solids content of the droplet $\left(\mathrm{s} \mathrm{mg}^{-1}\right)$. The maximum swelling $S_{\max }\left(\mathrm{cm}^{3} \mathrm{~g}^{-1}\right)$ of each droplet was calculated based on the approximation of the swollen particle as an ideal sphere ( $m$ is the dry mass of the droplet as $\mathrm{g})$ :

$$
S_{\max }=\frac{4}{3} A \sqrt{\frac{A}{\pi}} / m
$$

where $A$ is the cross-sectional area of the swollen particle $\left(\mathrm{cm}^{2}\right)$ measured by Image J software at the point of maximum swelling as observed in a selected frame of the video recording.

\section{RESULTS AND DISCUSSION}

\section{Dissolution of Organic Material during Pretreatment and Cooking}

Table 3 shows the effect of the hot-water pretreatment on the chemical composition of the feedstock. The most important factors responsible for the loss in feedstock mass were the hydrolysis of acetyl groups in xylan, the dissolution of degraded and intact hemicellulose fragments, and the partial removal of lignin and extractives (a decrease of $\sim 33 \%$ ). This could be inferred from the substantial decrease $(\sim 38 \%)$ in the relative content of xylose (i.e., the main monosaccharide moiety 
in xylan). In addition, a significant mass loss ( 29\%) of the minor hemicellulose component, glucomannan, took place. In contrast, the relative content of glucose (i.e., the monosaccharide moiety of cellulose and glucomannan) increased since, as expected, cellulose was not significantly affected by the pretreatment.

To investigate the effects of hot-water pretreatment on the combustion properties of BLs a series of BLs with varying compositions were prepared and tested. In contrast, the influence of cooking parameters on delignification was not the focus in this study. However, some information about the process was also revealed. Based on the kappa numbers, sawdust delignification was more effective with pretreatment than in the reference cooks without pretreatment ${ }^{[20]}$ (Table 2). The cooking yields were also similar for the same cooking times, except in the over-cooked cases (150 min). This led to the conclusion that the pretreatment of feedstock greatly facilitates delignification. Pretreatment generally rendered feedstock more accessible to cooking chemicals, but an additional reason for the enhanced delignification of the pretreated material was probably the cleavage of major ligninhemicellulose bonds during pretreatment. ${ }^{[48,49]}$

Table 4 lists the concentrations of aliphatic carboxylic acids (volatile acids and hydroxy acids), lignin, and other organics in the BLs obtained from pretreated and untreated sawdust subjected to different cooking methods. Differences among the BLs could be seen mainly in the content of aliphatic acids. This was expected since the deacetylation of xylan occurred during the pretreatment phase, yielding lower concentrations of acetic acid in the BLs from the pretreated feedstock than in those from the untreated sawdust. However, the changes in the concentrations of formic acid were not significant because it was produced from carbohydrates by peeling reactions, ${ }^{[26]}$ so its formation behavior was similar to that of hydroxy acids.

In the case of the pretreated sawdust, the content of volatile acids in the BLs was about half that of the hydroxy acids, whereas for the untreated sawdust, almost equivalent amounts were obtained. The results also showed that in all cases, the formation of hydroxy acids was more intense (by 23- 
$46 \%$ ) in the reaction using the pretreated sawdust than in that using the untreated sawdust. This difference could be also explained mainly by the removal of acetyl groups during the pretreatment stage: less alkali was needed to neutralize the volatile acids in the cooking stage, and more alkali (i.e., higher alkalinity) was available for various alkaline degradation reactions of the polysaccharides, resulting in greater degradation of hemicelluloses and cellulose in the feedstock matrix. A further contribution was probably made by formation of new reducing end groups in polysaccharides as well as by more effective penetration of the cooking chemicals due to the partial opening of the feedstock matrix under the pretreatment conditions. However, generally, no significant differences were found in the amounts of individual acids formed. Perhaps the only notable exception was that the formation of isosaccharinic acids, the most typical degradation products of xylan and glucomannan (i.e., xyloisosaccharinic and glucoisosaccharinic acids, respectively), was enhanced (an increase of 67$109 \%$ ) if the pretreatment stage was conducted before cooking.

As was already apparent from the kappa numbers in Table 2, the concentration of lignin was clearly lower in the $\mathrm{O}_{2}-\mathrm{NaOH}$ BLs than in the other BLs. In all cases, the ratio of lignin to aliphatic acids was in the range 1.3-1.7 with pretreatment and 1.1-1.8 without pretreatment (Table 4). The corresponding ratios of lignin to hydroxy acids were 2.0-2.5 with pretreatment and 2.2-3.6 without pretreatment; the corresponding ratios of lignin to volatile acids were 4.0-5.6 with pretreatment and 2.4-3.8 without pretreatment. In addition to the differences in the concentrations of the main groups of substances in the BLs, there were some characteristic differences in the dissolved lignin fractions of the BLs (Figure 1). It was noted that the MM values of the dissolved lignin are the lowest in the kraft BLs and the highest in the $\mathrm{O}_{2}-\mathrm{NaOH}$ BLs. Moreover, it could be inferred that under the pretreatment conditions, lower-MM lignin fragments were removed from the feedstock, ${ }^{[43]}$ and that after the sawdust matrix was changed by the pretreatment into a form more accessible to chemicals, the removal of higher-MM lignin was facilitated during the subsequent cooking phase. In addition, 
there seemed to be a general trend that the average MM of dissolved lignin decreases with increasing cooking time.

\section{Combustion Properties of Black Liquors}

Figure 2 summarizes the combustion properties of all the BLs studied, including the pyrolysis time, char burning time, and total burning time (i.e., pyrolysis time plus char burning time), together with the specific maximum swelling. It was noted that in all cases, the pyrolysis and char burning times decreased with increasing cooking time. In contrast, the specific maximum swelling increased with prolonged delignification. These findings were in agreement with those reported earlier for the combustion behavior of kraft BLs. ${ }^{[17]}$ Although the experimental strategy in this work involved preparing a large number of BLs with different compositions, it yielded only limited fundamental data on the detailed mechanisms behind the thermochemical effects. Of the BLs studied, the $\mathrm{O}_{2^{-}}$ $\mathrm{NaOH}$ liquor had the longest pyrolysis time. This was probably because these liquors had the lowest lignin-to-aliphatic acids ratio (1.1-1.4 vs. 1.4-1.8 for the others) and because, compared to lignin, aliphatic acids were relatively unstable when heated, ${ }^{[50]}$ thus readily releasing combustible volatiles. It was likely that the increase in the lignin concentration as a result of prolonged delignification also had a significant effect on the swelling behavior. In addition, kraft lignin with a lower MM than that of lignin from sulfur-free cooking formed char more easily and had shorter char burning times (Figure 1).

It was found that the pretreatment stage had a slight effect on the combustion behavior of BLs produced with the same cooking method. In contrast, with the same cooking time, the total burning times were longer (15-55\%) for the black liquors produced with sulfur-free cooking, especially the $\mathrm{O}_{2}-\mathrm{NaOH}$ cooking, than for the kraft BLs. With the same cooking time, the different black liquors produced from the untreated feedstock exhibited swelling in the following order: kraft BL > sodaAQ BL > $\mathrm{O}_{2}-\mathrm{NaOH} \mathrm{BL}$ (kraft BLs swelled typically 25-45\% more than the other BLs). It is known 
that during $\mathrm{O}_{2}-\mathrm{NaOH}$ delignification, smaller amounts of aliphatic acids are formed than during other cooking methods. ${ }^{[51]}$ This generates a larger amount of soluble hemicellulose residues, which generally decrease swelling. ${ }^{[17]}$ For the different black liquors from the pretreated feedstock, the swelling followed the order: kraft $\mathrm{BL} \cong \mathrm{O}_{2}-\mathrm{NaOH} \mathrm{BL}>$ soda-AQ BL. This indicated that during the pretreatment, alkali-stable hemicelluloses were partially removed.

\section{CONCLUSIONS}

In this study new data about the combustion properties of BLs produced from sulfur-free pulping (soda-AQ and $\mathrm{O}_{2}-\mathrm{NaOH}$ cooking) of silver birch feedstock are shown. It also examined the effects of hot-water pretreatment of feedstock prior to alkaline delignification on the combustion properties of BLs. Compared to conventional kraft BLs, the total burning times were noticeably longer for the sulfur-free BLs. However, no clear differences in the total burning times were observed for BLs prepared with the same cooking method from pretreated and untreated feedstock. However, it was found that, compared to the BLs from pretreated feedstock, the kraft and soda-AQ BLs from the untreated feedstock swell more and the $\mathrm{O}_{2}-\mathrm{NaOH}$ BLs swell less. The results also showed that especially in the case of untreated feedstock, the kraft BLs tend to swell more than the sulfur-free BLs. These findings of the combustion properties of sulfur-free hardwood BLs are considered valuable information for the control and design of recovery boilers.

\section{ACKNOWLEDGEMENTS}

Financial support from the Academy of Finland (to Chengcong Chen) within the framework of the International Doctoral Programme in Bioproducts Technology (PaPSaT) and Maj and Tor Nessling Foundation (to Joni Lehto) is gratefully acknowledged. Olli Byman and Petri Kilpeläinen 
from the Natural Resources Institute Finland (Luke) (formerly the Finnish Forest Research Institute, Metla) are also gratefully acknowledged for kindly providing feedstock materials for the cooking experiments. Special thanks are due to Mrs. Marja Salo for her skillful assistance with the analyses of aliphatic carboxylic acids.

\section{REFERENCES}

1. Rydholm, S.A. Pulping Processes; Interscience Publishers: New York, NY, USA, 1965.

2. Grace, T.; Malcolm, E.; Kocurek, M.J., Eds. Pulp and Paper Manufacture, Volume 5, Alkaline Pulping, 3rd edition; Joint Textbook Committee of the Paper Industry, TAPPI and CPPA: USA and Canada, 1989.

3. Martínez, J.; Reguant, J.; Salvadó, J.; Farriol, X. Soda-anthraquinone pulping of a softwood mixture: Applying a pseudo-kinetic severity parameter. Bioresour. Technol. 1997, 60(2), $161-167$.

4. Feng, Z.; Alén, R. Soda-AQ pulping of reed canary grass. Ind. Crops Prod. 2001, 14(1), 3139.

5. Francis, R.; Shin, S.; Omori, S.; Amidon, T.; Blain, T. Soda pulping of hardwoods catalyzed by anthraquinone and methyl substituted anthraquinones. J. Wood Chem. Technol. 2006, 26(2), 141-152.

6. Francis, R.; Bolton, T.; Abdoulmoumine, N.; Lavrykova, N.; Bose, S. Positive and negative aspects of soda/anthraquinone pulping of hardwoods. Bioresour. Technol. 2008, 99(17), 8453-8457.

7. Bose, S.K.; Omori, S.; Kanungo, D.; Francis, R.C.; Shin, N.-H. Mechanistic differences between kraft and soda/AQ pulping. Part 1: Results from wood chips and pulps. J. Wood Chem. Technol. 2009, 29(3), 214-226. 
8. Kanungo, D.; Francis, R.C.; Shin, N.-H. Mechanistic differences between kraft and soda/AQ pulping. Part 2: Results from lignin model compounds. J. Wood Chem. Technol. 2009, 29(3), 227-240.

9. World Health Organization. Some Chemicals Present in Industrial and Consumer Products, Food and Drinking-water: Anthraquinone. IARC Monogr. Eval. Carcinog. Risks Hum. World Health Organization, International Agency for Research on Cancer, Lyon, France, 2012, 101, 41-70.

10. Hart, P.W.; Rudie, A.W. Anthraquinone - A review of the rise and fall of a pulping catalyst. TAPPI J. 2014, 13(10), 23-31.

11. Kleppe, P.J.; Chang, H.-M.; Eckert, R.C. Delignification of high yield pulp with oxygen and alkali. I. Preliminary studies on southern pines. Pulp Pap. Mag. Can. 1972, 73, T400-T404.

12. Samuelson, O.; Sjöberg, L.A. Oxygen-alkali cooking of wood meal. Svensk Papperstidn. 1972, 75, 583-588.

13. Abrahamsson, K.; Samuelson, O.; Oxygen-alkali cooking of wood meal. III. Influence of oxygen pressure, carbon dioxide, and metal compounds. Svensk Papperstidn. 1973, 76, 480485.

14. Mosier, N.; Wyman, C.; Dale, B.; Dale, B.; Elander, R.; Lee, Y.Y.; Holtzapple, M.; Ladisch, M. Features of promising technologies for pretreatment of lignocellulosic biomass. Bioresour. Technol. 2005, 96(6), 673-686.

15. Kamm, B.; Kamm, M.; Gruber, P.R.; Kromus, S. Biorefinery systems - an overview. In Biorefineries - Industrial Processes and Products, Status Quo and Future Directions Vol. 1; Kamm, B.; Gruber, P.R.; Kamm, M., Eds.: Wiley-VCH, Weinheim, Germany, 2006; 3-40. 16. Carvalheiro, F.; Duarte, L.C.; Gírio, F.M. Hemicellulose biorefineries: A review on biomass pretreatments. J. Sci. Ind. Res. 2008, 849-864. 
17. Alén, R. Structure and chemical composition of biomass feedstocks. In Biorefining of Forest Resources; Alén, R., Ed.: Paper Engineers``Association, Helsinki, Finland, 2011, 55-114.

18. Lehto, J.; Alén, R. Chemical pretreatments of wood chips prior to alkaline pulping: A review of pretreatment alternatives, chemical aspects of the resulting liquors, and pulping outcomes. BioResources. 2015, 10(4), 8604-8656.

19. Lehto, J. Advanced Biorefinery Concepts Integrated to Chemical Pulping; Ph.D. Thesis: University of Jyväskylä, Laboratory of Applied Chemistry, Jyväskylä, Finland, 2015.

20. Yoon, S.-H.; Macewan, K.; van Heiningen, A.R. Hot-water pre-extraction from loblolly pine (Pinus taeda) in an integrated forest products biorefinery. TAPPI J. 2008, 7(6), 27-32.

21. Lehto, J.; Alén, R.; Malkavaara, P. Multivariate correlation between analytical data for various organics dissolved during autohydrolysis of silver birch (Betula pendula) chips and treatment conditions. BioResources. 2014, 9(3), 4958-4970.

22. Walton, S.L.; Hutto D.; Genco J.M.; Walsum G.P.; van Heiningen A.R. Pre-extraction of hemicelluloses from hardwood chips using an alkaline wood pulping solution followed by kraft pulping of the extracted wood chips. Ind. Eng. Chem. Res. 2010, 49(24), 12638-12645.

23. Park, Y.C.; Kim, J.S. Comparison of various alkaline pretreatment methods of lignocellulosic biomass. Energy. 2012, 47(1), 31-35.

24. Lehto, J.; Alén, R. Alkaline pre-treatment of hardwood chips prior to delignification. J. Wood Chem. Technol. 2013, 33(2), 77-91.

25. Sjöström, E., Wood Chemistry - Fundamentals and Applications, 2nd edition; Academic Press: San Diego, CA, USA, 1993.

26. Alén, R. Basic chemistry of wood delignification. In Forest Products Chemistry; Stenius, P., Ed.; Fapet Oy: Helsinki, Finland, 2000; 58-104. 
27. Niemelä, K.; Alén, R. Characterization of pulping liquors. In Analytical Methods in Wood Chemistry, Pulping, and Papermaking; Sjöström, E.; Alén, R., Eds.; Springer-Verlag: Heidelberg, Germany, 1999, 193-231.

28. Hupa, M.; Solin, P.; Hyöty, P. Combustion behaviour of black liquor droplets. J. Pulp Pap. Sci. 1987, 13(2), 67-72.

29. Milanova, E. Variables affecting the swelling of kraft black liquor solids. J. Pulp Pap. Sci. 1988, 14(4), 95-102.

30. Miller, P.T.; Clay, D.T.; Lonsky, W.F.W. The influence of composition on the swelling of kraft black liquor during pyrolysis. Chem. Eng. Comm. 1989, 75(1), 101-120.

31. Frederick, W.J.; Noopila, T.; Hupa, M. Swelling of spent pulping liquor droplets during combustion. J. Pulp Pap. Sci. 1991, 17(5), 164-170.

32. Noopila, T.; Alén, R.; Hupa, M. Combustion properties of laboratory-made black liquors. J. Pulp Pap. Sci. 1991, 17(4), 105-109.

33. Alén, R.; Hupa, M.; Noopila, T. Combustion properties of organic constituents of kraft black liquors. Holzforschung. 1992, 46(4), 337-342.

34. Frederick, W.J.; Hupa, M. The effects of temperature and gas composition on swelling of black liquor droplets during devolatilization. J. Pulp Pap. Sci. 1994, 20(10), 274-282.

35. Alén, R. Swelling behaviour of kraft black liquor and its organic constituents. Bioresour. Technol. 1994, 49(2), 99-103.

36. Alén, R. Analysis of degradation products: A new approach to characterizing the combustion properties of kraft black liquors. J. Pulp Pap. Sci. 1997, 23(2), 62-66.

37. Whitty, K.; Backman, R.; Forssén, M.; Hupa, M.; Rainio, J.; Sorvari, V. Liquor-to-liquor differences in combustion and gasification processes: Pyrolysis behaviour and char reactivity. J. Pulp Pap. Sci. 1997, 23(3), 119-128. 
38. Louhelainen, J. Changes in the Chemical Composition and Physical Properties of Wood and Nonwood Black Liquors during Heating; PhD Thesis: University of Jyväskylä, Laboratory of Applied Chemistry, Jyväskylä, Finland, 2003.

39. Whitty, K.; Backman, R.; Hupa, M. Influence of pressure on pyrolysis of black liquor: 1. Swelling. Bioresour. Technol 2008, 99(3), 663-670.

40. Adams, T.N. (Ed.). Kraft Recovery Boilers; TAPPI Press: Atlanta, GA, USA, 1997.

41. Tunc, M.S.; van Heiningen, A.R.P. Autohydrolysis of mixed southern hardwoods: Effect of P-factor. Nord. Pulp Pap. Res. J. 2009, 24, 46-51.

42. Swan, B. Isolation of acid-soluble lignin from the Klason lignin determination. Svensk Papperstidn. 1965, 68, 791-795.

43. Lehto, J.; Pakkanen, H.; Alén, R. Molecular mass distribution of sulfur-free lignin from alkaline pulping preceded by hot-water-extraction. Appita J. 2015, 68, 149-158.

44. Alén, R.; Jännäri, P.; Sjöström, E. Gas-liquid chromatographic determination of volatile fatty acids $\mathrm{C}_{1}-\mathrm{C}_{6}$, and lactic acid as their benzyl esters on a fused-silica capillary column. Finn. Chem. Lett. 1985, 12(5), 190-192.

45. Alén, R.; Niemelä, K.; Sjöström, E. Gas-liquid chromatographic separation of hydroxy monocarboxylic acids and dicarboxylic acids on a fused-silica capillary column. J. Chromatogr. A. 1984, 301(1), 273-276.

46. Alén, R.; Hartus, T. UV spectrophotometric determination of lignin from alkaline pulping liquors. Cell. Chem. Technol. 1988, 22(6), 613-618.

47. Pakkanen, H.; Alén, R. Molecular mass distribution of lignin from the alkaline pulping of hardwood, softwood, and wheat straw. J. Wood Chem. Technol. 2012, 32(4), 279-293.

48. Li, J.; Gellerstedt, G. Improved lignin properties and reactivity by modifications in the autohydrolysis process of aspen wood. Ind. Crops Prod. 2008, 27, 175-181. 
49. Bujanovic, B.M.; Goundalkar, M.J.; Amidon, T.E. Increasing the value of a biorefinery based on hot-water extraction: Lignin products. TAPPI J., 2012, 11(1), 19-26.

50. Lehto, J.; Pakkanen, H.; Alén, R. Molecular mass distribution of sulfur-free lignin from alkaline pulping preceded by hot-water-extraction. Appita J. 2015, 68, 149-158.

51. Alén, R.; Rytkönen, S.; McKeough, P. Thermogravimetric behavior of black liquors and their organic constituents. J. Anal. Appl. Pyrolysis 1995, 31, 1-13.

52. Salmela, M., Description of Oxygen-alkali Delignification of Kraft Pulp Using Analysis of Dissolved Material; Ph.D. Thesis: University of Jyväskylä, Laboratory of Applied Chemistry, Jyväskylä, Finland, 2007. 